\title{
Optical Sensing for Evaluating the Severity of Disease Caused by Cladosporium sp. in Barley under Warmer Conditions
}

\author{
Dohyeok Oh $\mathbb{B}^{1}$, Jae-Hyun Ryu $\mathbb{D}^{1}{ }^{1}$, Sehee $\mathrm{Oh}^{1}$, Hoejeong Jeong ${ }^{1}$, Jisung Park ${ }^{1}$, Rae-Dong Jeong ${ }^{2}$, \\ Wonsik $\mathrm{Kim}^{3}$ and Jaeil Cho (Di) ${ }^{1 *}$ \\ ${ }^{1}$ Department of Applied Plant Science, Chonnam National University, Gwangju 61186, Korea \\ ${ }^{2}$ Department of Applied Biology, Institute of Environmentally Friendly Agriculture, Chonnam National University, \\ Gwangju 61185, Korea \\ ${ }^{3}$ Institute for Agro-Environmental Sciences/National Agriculture and Food Research Organization, 3-1-3 Kannondai, \\ Tsukuba, Ibaraki, Japan
}

(Received on December 1, 2017; Revised on February 4, 2018; Accepted on February 28, 2018)

Crop yield is critically related to the physiological responses and disease resistance of the crop, which could be strongly affected by high temperature conditions. We observed the changes in the growth of barley under higher than ambient air-temperature conditions using a temperature gradient field chamber (TGFC) during winter and spring. Before the stem extension stage of barley growth, Cladosporium sp. spontaneously appeared in the TGFC. The severity of disease became serious under warmer temperature conditions. Further, the stomata closed as the severity of the disease increased; however, stomatal conductance at the initial stage of disease was higher than that of the normal leaves. This was likely due to the Iwanov effect, which explains that stressed plants rapidly and transiently open their stomata before longer-term closure. In this study, we tested three optical methods: soil-plant analysis development (SPAD)

\footnotetext{
*Corresponding author.

Phone) +82-62-530-2056, FAX) +82-62-530-2059

E-mail) chojaeil@gmail.com

ORCID

J Cho

https://orcid.org/0000-0002-3375-4357

$\mathrm{D} \mathrm{Oh}$

https://orcid.org/0000-0002-8783-4870

J-H Ryu

https://orcid.org/0000-0002-5609-2739

(c) This is an Open Access article distributed under the terms of the Creative Commons Attribution Non-Commercial License (http:// creativecommons.org/licenses/by-nc/4.0) which permits unrestricted noncommercial use, distribution, and reproduction in any medium, provided the original work is properly cited.
}

Articles can be freely viewed online at www.ppjonline.org. chlorophyll index, photochemical reflectance index (PRI), and maximum quantum yield (Fv/Fm). These rapid evaluation methods have not been used in studies focusing on disease stress, although some studies have used these methods to monitor other stresses. These three indicative parameters revealed that diseased barley exhibited lower values of these parameters than normal, and with the increase in disease severity, these values declined further. Our results will be useful in efficient monitoring and evaluation of crop diseases under future warming conditions.

Keywords : warmer condition, Cladosporium sp., barley, chlorophyll index, photochemical reflectance index (PRI), maximum quantum yield ( $\mathrm{Fv} / \mathrm{Fm})$

Handling Associate Editor : Lee, Jungkwan

Annual global temperature has increased by approximately $0.4^{\circ} \mathrm{C}$ since 1980 (Hartmann et al., 2013). Achieving maximum crop yield, determined by the crop's genetic potential, has become harder because of increasing negative impacts such as vulnerability to crop disease epidemics caused mainly by global warming conditions (Lobell et al., 2011). Indeed, the physiological response of crops and disease resistance can be largely affected by above optimum level (Pounds et al., 2006). Thus, we observed the changes in the growth of barley under higher than normal air-temperature conditions using a temperature gradient field chamber (TGFC) at the Chonnam National University campus during winter 2016 to spring 2017 (Fig. 1). The operation of an air heater and ventilator in the TGFC was designed to 


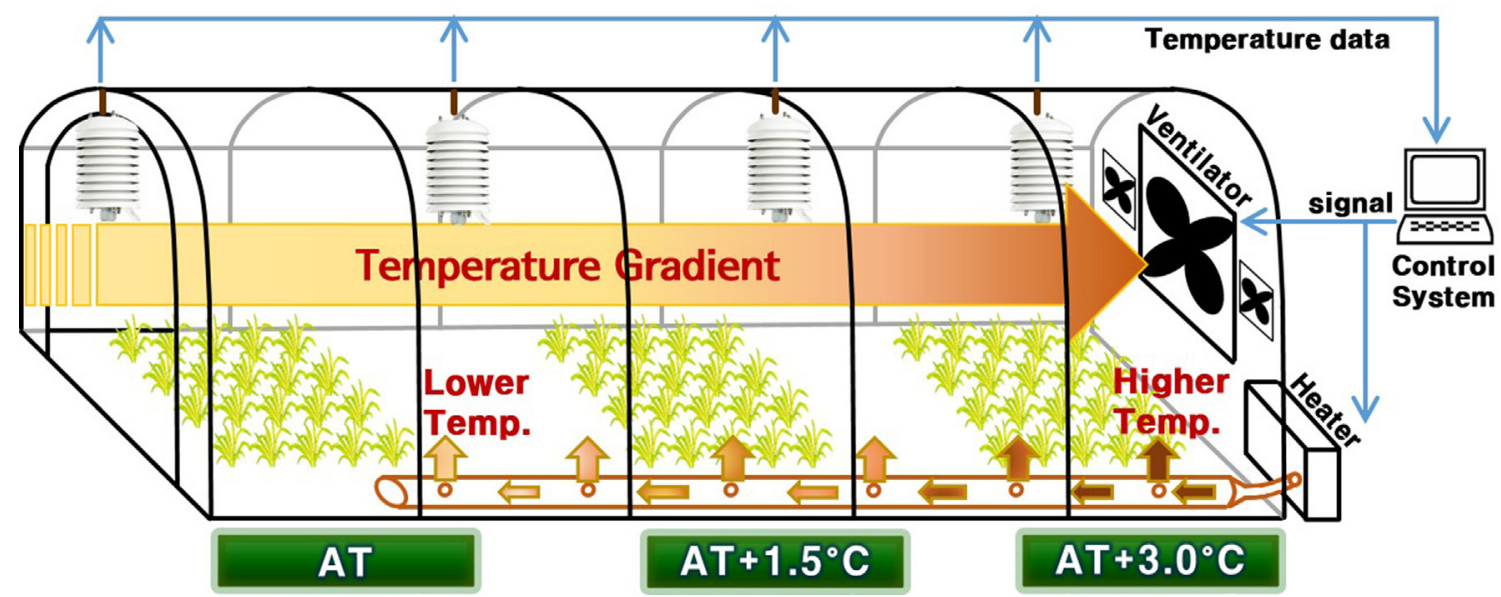

Fig. 1. A schematic illustration of the temperature gradient field chamber (TGFC) for exposing barley to the gradient warm conditions by $0^{\circ} \mathrm{C}$ to $3^{\circ} \mathrm{C}$.

maintain $+3.0^{\circ} \mathrm{C}$ higher air-temperature at the innermost part of the chamber $\left(\mathrm{AT}+3.0^{\circ} \mathrm{C}\right)$ and ambient temperature was achieved at the entrance of the chamber (AT) (Horie et al., 1995). The central position $\left(\mathrm{AT}+1.5^{\circ} \mathrm{C}\right)$ of chamber had approximately $+1.5^{\circ} \mathrm{C}$ higher air-temperature than that of the AT. At each location, AT, AT $+1.5^{\circ} \mathrm{C}$, and AT + $3.0^{\circ} \mathrm{C}$, the three ports for planting barley were located.

Before the stem extension stage of barley growth, Cladosporium sp., a fungal pathogen, spontaneously appeared in the TGFC. The isolate was purified by a single spore isolation technique and identified based on morphological characteristics and genetic analysis. For fungal identification, the genomic DNA was isolated from the fungus using a DNA extraction kit (Intron, Daejeon, Korea), according to the manufacturer's protocols. The extracted DNA was purified using a QIAquick ${ }^{\circledR}$ DNA purification kit (Qiagen, Valencia, CA, USA). The primers, ITS1 primer (5'-TCGGTAGGTGAACCTGCGG-3') and

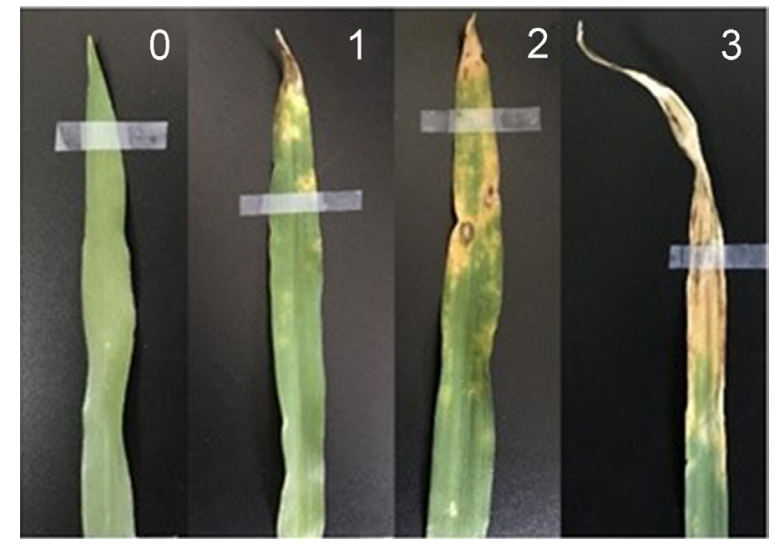

Fig. 2. Visible images for the severity level of Cladosporium sp. disease in barley.
ITS4 primer (5'-TCCTCCGCTTATTGATATGC-3'), were used for the PCR. Gene sequencing and a blast search were requested from a commercial analysis service (Macrogen Inc., Daejeon, Korea).

In this study, we aim to test optical methods to rapidly evaluate the disease conditions. First, to prepare a baseline data for identifying the disease incidence, we conventionally classified the level of damage caused by the disease using the unaided eye, as $0,1,2$, or 3 , as is typical, progressing from initial damage to fatal levels, respectively (Fig. 2). Then, the area of one port $(43.00 \mathrm{~cm}$ $\times 73.00 \mathrm{~cm})$ was separated into 16 sub-rectangular areas $(10.75 \mathrm{~cm} \times 18.25 \mathrm{~cm})$ to investigate the incidence of disease. Thus, each location had 48 sub-rectangular areas in three ports. Using the maximum level among foliage in one sub-rectangle area, the proportions of each level in one location were represented (Fig. 3). The severity of the disease increased in the order of increasing air-

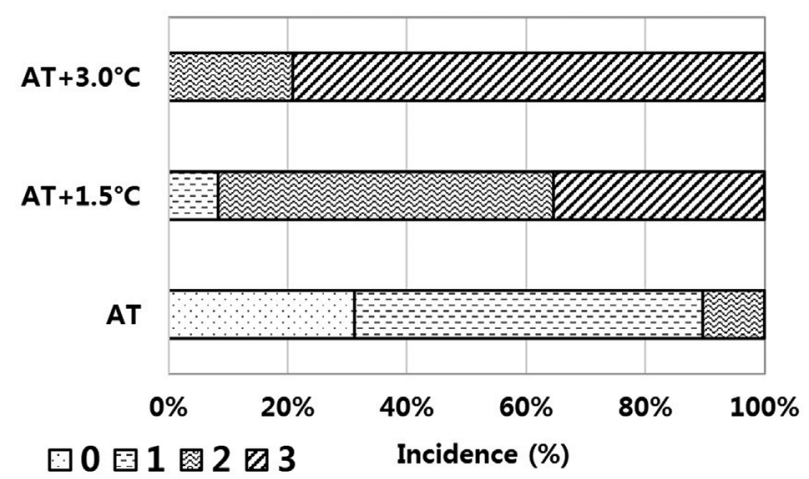

Fig. 3. Incidence (\%) of the worst disease levels that occurred at the different air-temperature conditions (i.e., AT, AT $+1.5^{\circ} \mathrm{C}$, and $\mathrm{AT}+3.0^{\circ} \mathrm{C}$ ) in barley. 
temperature conditions. Given that Cladosporium sp. can be spread by air-borne spores (Peternel et al., 2004), the differential incidences of this fungal pathogen at the notsegregated three locations (i.e., AT, AT $+1.5^{\circ} \mathrm{C}$, and AT $+3.0^{\circ} \mathrm{C}$ ) could be affected by air temperature condition. Indeed, Cladosporium sp. is often occurred in summer than winter. This finding indicated the occurrence probability of Cladosporium sp. on barley will become higher under warmed condition.

To maintain a sustainable agricultural system under the conditions of global warming, rapid methods to evaluate disease severity through monitoring are highly necessary (Wolfert et al., 2017). Optical sensing is one of the best techniques to rapidly provide adequate estimation regarding the degree of infection (Franke and Menz, 2007). Optical sensors basically depend on the distinctive feature of the spectrum of reflection and absorption caused by the state of the photosynthetic pigments in the foliage canopy (e.g., chlorophyll and carotenoids) and leaf structure, as well as leaf area and leaf area contents (Jackson, 1986). However, in previous studies, this method was used for monitoring environmental stresses, such as water deficits (e.g., Winkel et al., 2002), but not for disease stress. Thus, in this study, we applied three optical methods to monitor diseased barley: soil-plant analysis development (SPAD) chlorophyll index, photochemical reflectance index (PRI), and maximum quantum yield $(\mathrm{Fv} / \mathrm{Fm})$. Further, stomatal conductance was also measured to analyze the results from these three optical sensors. These measurements were taken using five sample leaves for each of the four disease levels in $\mathrm{AT}+3 \cdot 0^{\circ} \mathrm{C}$ at noon on February 13,2017 . The portable instruments for SPAD, PRI, Fv/Fm, and $g_{s}$ values were used five times which was evenly spread across one sample leaf.

Stomatal closure is critically affected in response to disease-caused stress (Smith et al., 1986). We measured $g_{s}\left(\mathrm{mmol} \mathrm{m} \mathrm{m}^{-2} \mathrm{~s}^{-1}\right)$ using a porometer (SC-1 Porometer, Decagon Devices Inc., WA, USA). As the disease level increased, $g_{s}$ was distinctly decreased (Fig. 4A). However, $g_{s}$ of normal leaves (level 0) was less than that in the initial disease level (level 1). This transient stomatal opening might be a result of the Iwanov Effect denoted by Iwanov (1928) and various research (e.g., Jones, 1999; Vysotskaya et al., 2003). It explains that stressed plants rapidly and transiently open their stomata before longer-term closure (Jones, 1999). In this study, such phenomenon also have been replicated in Cladosporium sp. on the barley. Therefore, although $g_{s}$ negatively responded to the severity of disease, except the early infection, $g_{s}$ is probably not suitable for quantitative evaluation.

A portable chlorophyll meter (SPAD-502 leaf chlorophyll meter, Minolta Corp., Osaka, Japan) can measure leaf
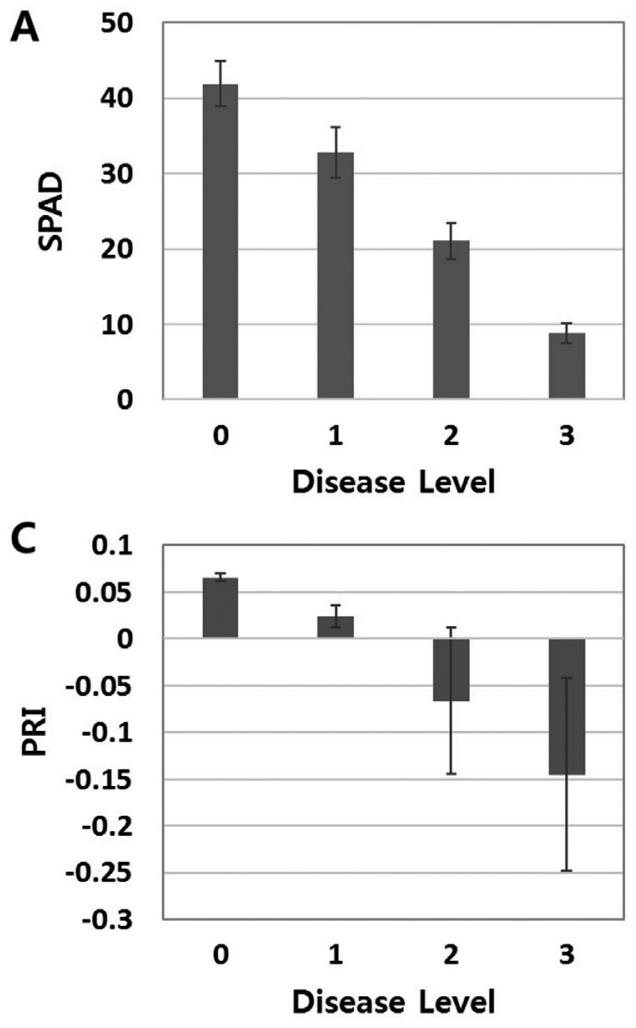
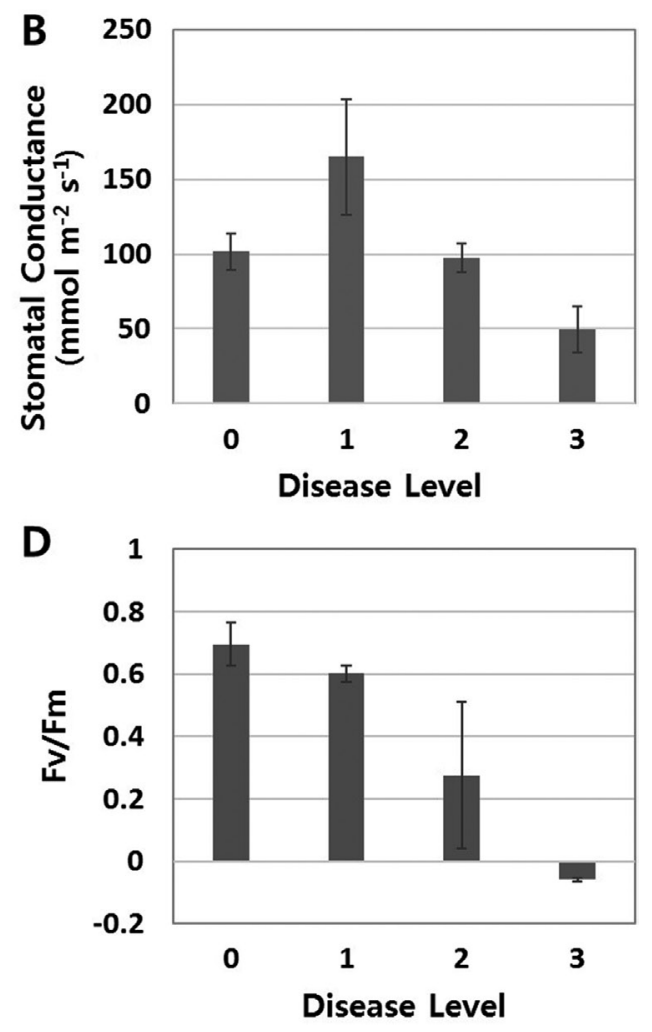

Fig. 4. Measurements of (A) stomatal conductance (mmol m$\left.{ }^{-2} \mathrm{~s}^{-1}\right)$, (B) SPAD chlorophyll index, (C) PRI, and (D) Fv/Fm for leaves at each disease level. 
chlorophyll in a nondestructive manner. Measurement of SPAD values was primarily based on the differential transmission of red and near infra-red (NIR) radiations. Previous studies have reported the relationship of SPAD values to leaf nitrogen and chlorophyll concentrations (e.g., Uddling et al., 2007). The SPAD values at level 0 gradually decreased as the disease worsened (Fig. 4B). This could correspond to destroyed chlorophyll content because of the damage by Cladosporium sp. In fact, because the visual classification from 0 to 3 in this study was based on the change in greenness caused by chlorophyll concentration, the SPAD values and severity levels exhibited a significant correlation. Therefore, SPAD was the closest to the farmer's recognition of disease severity, but it was not useful for early detection of the disease.

PRI is defined by using two contributing reflectances: ( $\rho)$ at $531 \mathrm{~nm}$ and $570 \mathrm{~nm}$ wavelengths (i.e., $(\rho 531-\rho 570)$ $/(\rho 531+\rho 570))$ (Gamon et al., 1992). It is positively sensitive to changes in carotenoid pigments of the foliage (Filella et al., 2009). The xanthophyll pigment cycle of carotenoid pigments is closely related to photosynthetic productivity and stress (Gamon et al., 1992; Stylinski et al., 2002). Therefore, measuring the PRI has recently attracted attention for the parameterization of canopy light use efficiency and assessing plant stress (e.g., photo-inhibition, soil moisture stress, aging, ozone stress) (Gamon et al., 1992, 2001; Meroni et al., 2008; Stylinski et al., 2002). However, the change in PRI relative to disease is not well documented. In this study, we measured the PRI using a portable PRI meter (PRI200, Photon Systems Instruments, Drasov, Czech Republic). As the disease level increased, the PRI value at noon decreased (Fig. 4C). The lower PRI values of a state of physiological stress were caused by a relatively reduced carotenoid pigment concentrations (Gamon and Berry, 2012). Indeed, carotenoid pigments protect cells against the light induced thermal processing (Barry et al., 1990). Therefore, such stress values facilitate better understanding of how photosynthetic performance decreases due to the disease process (Gamon et al., 2001).

$\mathrm{Fv} / \mathrm{Fm}$ is a ratio of variable chlorophyll fluorescence $(\mathrm{Fv})$ over the maximum fluorescence value (Fm) (Mohammed et al., 1995). Thus, it can represent potential photochemical activity (Öquist and Wass, 1988). An unstressed plant has approximately 0.8 , regardless of the type of plant. If the $\mathrm{Fv} / \mathrm{Fm}$ is 0.4 , it means that the photosynthesis capacity is reduced by half. We measured the Fv/Fm at noon using by a portable fluorometer (FluorPen FP100, Photon Systems Instruments, Brno, Czech Republic) and a dark-clip which provided dark adaptation for at least $20 \mathrm{~min}$ to get the basic level of chlorophyll fluorescence yield. The Fv/Fm values decreased with increasing disease level (Fig. 4D). However, the $\mathrm{Fv} / \mathrm{Fm}$ value of the normal leaf was close to 0.8 , but not 0.8 . This might have occurred because of exposing barley to cold stress during winter. At disease level 2, the Fv/Fm had declined below 0.4. This will be valuable for realizing the disease condition by assessing chlorophyll damage.

On the basis of our results, which demonstrated the increased occurrence of Cladosporium sp. on barley under warm conditions, agricultural systems have to be prepared for global warming. However, conventional sampling and laboratory analysis methods to identify crop disease are relatively slow and expensive. In this study, we examined three optical methods that successfully represented the severity of the disease in barley. Our results will be useful in the efficient monitoring and realizing of crop diseases.

\section{Acknowledgments}

We would like to thank to editor and anonymous reviewers, whose comments were valuable for revising this manuscript. This research was supported by Rural Development Administration (Project No. PJ01277502), Republic of Korea.

\section{References}

Barry, P., Young, A. J. and Britton, G. 1990. Photodestruction of pigments in higher plants by herbicide action: I. The effect of DCMU (diuron) on isolated chloroplasts. J. Exp. Bot. 41:123129.

Franke, J. and Menz, G. 2007. Multi-temporal wheat disease detection by multi-spectral remote sensing. Precis. Agric. 8:161172.

Filella, I., Porcar-Castell, A., Munné-Bosch, S., Bäck, J., Garbulsky, M. F. and Peñuelas, J. 2009. PRI assessment of longterm changes in carotenoids/chlorophyll ratio and short-term changes in de-epoxidation state of the xanthophyll cycle. Int. J. Remote Sens. 30:4443-4455.

Gamon, J. A. and Berry, J. A. 2012. Facultative and constitutive pigment effects on the Photochemical Reflectance Index (PRI) in sun and shade conifer needles. Isr. J. Plant Sci. 60:85-95.

Gamon, J. A., Field, C. B., Fredeen, A. L. and Thayer, S. 2001. Assessing photosynthetic downregulation in sunflower stands with an optically-based model. Photosynth. Res. 67:113-125.

Gamon, J. A., Peñuelas, J. and Field, C. B. 1992. A narrowwaveband spectral index that tracks diurnal changes in photosynthetic efficiency. Remote Sens. Environ. 41:35-44.

Hartmann, D. L., Klein Tank, A. M. G., Rusticucci, M., Alexander, L. V., Brönnimann, S., Charabi, Y., Dentener, F. J., Dlugokencky, E. J., Easterling, D. R., Kaplan, A., Soden, B. J., Thorne, P. W., Wild, M. and Zhai, P. M. 2013. Observa- 
tions: atmosphere and surface. In: Climate change 2013: the physical science basis, eds. T. Stocker, D. Qin, G.-K. Plattner, M. Tignor, S. K. Allen, J. Boschung, A. Nauels, Y. Xia, V. Bex and P. M. Midgley, pp. 159-254. Contribution of Working Group I to the Fifth Assessment Report of the Intergovernmental Panel on Climate Change. Cambridge University Press, Cambridge, UK, NY, USA.

Horie, T., Nakagawa, H., Nakano, J., Hamotani, K. and Kim, H. Y. 1995. Temperature gradient chambers for research on global environment change. III. A system designed for rice in Kyoto, Japan. Plant Cell Environ. 18:1064-1069.

Iwanov, L. 1928. Zur Methodik der Transpirations-bestimmungam Standort. Ber. Deutsch. Bot. Ges. 46:306-310.

Jackson, R. D. 1986. Remote sensing of biotic and abiotic plant stress. Annu. Rev. Phytopathol. 24:265-287.

Jones, H. G. 1999. Use of thermography for quantitative studies of spatial and temporal variation of stomatal conductance over leaf surfaces. Plant Cell Environ. 22:1043-1055.

Lobell, D. B., Schlenker, W. and Costa-Roberts, J. 2011. Climate trends and global crop production since 1980. Science 333:616-620.

Meroni, M., Rossini, M., Picchi, V., Panigada, C., Cogliati, S., Nali, C. and Colombo, R. 2008. Assessing steady-state fluorescence and PRI from hyperspectral proximal sensing as early indicators of plant stress: the case of ozone exposure. Sensors (Basel) 8:1740-1754.

Mohammed, G. H., Binder, W. D. and Gillies, S. L. 1995. Chlorophyll fluorescence: a review of its practical forestry applications and instrumentation. Scand. J. Forest Res. 10:383-410.

Öquist, G. and Wass, R. 1988. A portable, microprocessor operated instrument for measuring chlorophyll fluorescence kinetics in stress physiology. Physiol. Plant. 73:211-217.
Peternel, R., Culig, J. and Hrga, I. 2004. Atmospheric concentrations of Cladosporium spp. and Alternaria spp. spores in Zagreb (Croatia) and effects of some meteorological factors. Ann. Agric. Environ. Med. 11:303-307.

Pounds, J. A., Bustamante, M. R., Coloma, L. A., Consuegra, J. A., Fogden, M. P., Foster, P. N., Marca, E. L., Masters, K. L., Merino-Viteri, A., Puschendorf, R., Ron, S. R., SánchezAzofeifa, G. A., Still, C. J. and Young, B. E. 2006. Widespread amphibian extinctions from epidemic disease driven by global warming. Nature 439:161-167.

Smith, R. C. G., Heritage, A. D., Stapper, M. and Barrs, H. D. 1986. Effect of stripe rust (Puccinia striiformis West.) and irrigation on the yield and foliage temperature of wheat. Field Crops Res. 14:39-51.

Stylinski, C. D., Gamon, J. A. and Oechel, W. C. 2002. Seasonal patterns of reflectance indices, carotenoid pigments and photosynthesis of evergreen chaparral species. Oecologia 131:366-374.

Uddling, J., Gelang-Alfredsson, J., Piikki, K. and Pleijel, H. 2007. Evaluating the relationship between leaf chlorophyll concentration and SPAD-502 chlorophyll meter readings. Photosynth. Res. 91:37-46.

Vysotskaya, L. B., Kudoyarova, G. R., Veselov, S. and Jones, H. G. 2003. Unusual stomatal behaviour on partial root excision in wheat seedlings. Plant Cell Environ. 27:69-77.

Winkel, T., Méthy, M. and Thénot, F. 2002. Radiation use efficiency, chlorophyll fluorescence, and reflectance indices associated with ontogenic changes in water-limited Chenopodium quinoa leaves. Photosynthetica 40:227-232.

Wolfert, S., Ge, L., Verdouw, C. and Bogaardt, M. J. 2017. Big data in smart farming-a review. Agric. Syst. 153:69-80. 